\title{
Duarte galactose-1-phosphate uridyl transferase genotypes are not associated with ovarian cancer risk
}

\section{Citation}

Merritt, Melissa A., Joanne Kotsopoulos, Daniel W. Cramer, Susan E. Hankinson, Kathryn L. Terry, and Shelley S. Tworoger. 2012. "Duarte Galactose-1-Phosphate Uridyl Transferase Genotypes Are Not Associated with Ovarian Cancer Risk." Fertility and Sterility 98 (3) (September): 687-691. doi:10.1016/j.fertnstert.2012.05.045.

\section{Published Version}

doi:10.1016/j.fertnstert.2012.05.045

\section{Permanent link}

http://nrs.harvard.edu/urn-3:HUL.InstRepos:27332427

\section{Terms of Use}

This article was downloaded from Harvard University's DASH repository, and is made available under the terms and conditions applicable to Other Posted Material, as set forth at http:// nrs.harvard.edu/urn-3:HUL.InstRepos:dash.current.terms-of-use\#LAA

\section{Share Your Story}

The Harvard community has made this article openly available.

Please share how this access benefits you. Submit a story.

Accessibility 
Fertil Steril. 2012 September ; 98(3): 687-691. doi:10.1016/j.fertnstert.2012.05.045.

\title{
Duarte GALT genotypes are not associated with ovarian cancer risk
}

\author{
Melissa A. Merritt, Ph.D. a,b,c, ${ }^{*}$, Joanne Kotsopoulos, Ph.D.d, Daniel W. Cramer, M.D., \\ Sc.D..$^{a, b}$, Susan E. Hankinson, Sc.D. ${ }^{a, e, f}$, Kathryn L. Terry, Sc.D. ${ }^{a, b}$, and Shelley S. Tworoger, \\ Ph.D. ${ }^{a, e}$ \\ aDepartment of Epidemiology, Harvard School of Public Health, Boston, MA \\ bOB/GYN Epidemiology Center, Brigham and Women's Hospital, Harvard Medical School, \\ Boston, MA \\ 'Department of Biostatistics and Computational Biology, Dana-Farber Cancer Institute, Boston, \\ MA \\ dWomen's College Research Institute, Dalla Lana School of Public Health, University of Toronto, \\ Toronto, Ontario, Canada \\ eChanning Laboratory, Department of Medicine, Brigham and Women's Hospital and Harvard \\ Medical School \\ fDivision of Biostatistics and Epidemiology, University of Massachusetts, Amherst, MA
}

\section{Abstract}

Objective-To investigate whether Galactose-1-phosphate uridyl transferase (GALT) variant genotypes were associated with epithelial ovarian cancer risk and to determine if this association was modified by lactose intake.

Design-two prospective cohort studies and a case-control study.

Setting-Academic institution.

Patient(s)—992 cases and 1050 population-based controls from a New England case-control study and 240 cases and 900 controls from the Nurses' Health Studies.

Intervention(s)-None.

Main Outcome Measure(s)-Genotyping of the N314D variant and the 4-bp deletion (-119delGTCA) of GALT using the Taqman 5' nuclease assay. Duarte1 (D1) genotype individuals have a missense mutation (N314D) associated with normal GALT activity unless it occurs together with an associated 4-bp deletion leading to reduced GALT activity (Duarte2 or D2).

\footnotetext{
(C) 2012 American Society for Reproductive Medicine. Published by Elsevier Inc. All rights reserved.

"Corresponding author: Melissa A. Merritt, Ph.D., Harvard School of Public Health, Dept of Epidemiology and Brigham and Women's Hospital, Obstetrics and Gynecology Epidemiology Center, 221 Longwood Ave, Boston, MA 02115, merritt@jimmy.harvard.edu.

The authors (M.A.M, J.K., D.W.C., S.E.H., K.L.T., S.S.T.) have no conflicts of interest to disclose.

Publisher's Disclaimer: This is a PDF file of an unedited manuscript that has been accepted for publication. As a service to our customers we are providing this early version of the manuscript. The manuscript will undergo copyediting, typesetting, and review of the resulting proof before it is published in its final citable form. Please note that during the production process errors may be discovered which could affect the content, and all legal disclaimers that apply to the journal pertain.
} 
Result(s)—Logistic regression analysis identified no association between D1/D2 genotypes and ovarian cancer risk (pooled RR, 1.1 (95\% CI, 0.8-1.5) for D1 and 1.0 (95\% CI, 0.7-1.4) for D2). We did not observe a significant interaction between D1 and D2 genotypes in analyses stratified by level of lactose intake $\left(\mathrm{P}_{\text {interaction }} \geq 0.3\right)$.

Conclusion(s)—D1 and D2 genotypes do not appear to play a role in the association between galactose intake, possible ovarian dysfunction and the link with ovarian cancer.

\section{Keywords}

Duarte GALT; ovarian cancer; dairy foods; lactose

\section{Introduction}

High dietary intake of lactose has been associated with increased risk of ovarian cancer (1, 2) presumably through the toxic effects of un-metabolized galactose (lactose metabolite) on the ovary and associated changes in the ovarian-pituitary axis (3). Functional polymorphisms in galactose-1-phosphate uridyl transferase (GALT), an enzyme responsible for the interconversion of galactose-1-phosphate and glucose-1-phosphate, have been identified as a cause of galactosemia resulting in developmental problems and early menopause in girls. A more common mutation involving replacement of asparagine with aspartic acid (N314D) occurs in approximately $10 \%$ of Caucasians and has been inconsistently associated with reduced GALT activity (4). A 4-bp deletion (-119delGTCA) in the $5^{\prime}$ proximal region of $G A L T$ was identified in cis with N314D and studies suggested that this 4-bp deletion is specifically related to reduced GALT activity (5-8). Hence the combination of these two variants distinguishes Duarte 1 (D1) with relatively normal GALT activity from Duarte 2 (D2) with reduced GALT activity.

The relationship between N314D and ovarian cancer has been investigated in several studies (9-13). Five studies found similar GALT enzyme activity and frequencies of N314D mutations among ovarian cancer cases overall versus controls (9-13); however, two studies found an increased risk of serous (14) or endometrioid/clear cell (15) tumors in patients that were heterozygous or homozygous variant for N314D, respectively. None of these studies evaluated D1 or D2 genotypes in relation to ovarian cancer risk. Thus, we genotyped both N314D and the 4-bp deletion in epithelial ovarian cancer cases and controls from a New England based case-control study (NECC) and in a nested case-control study within the Nurses' Health Studies (NHS/NHSII). The objective of our study was to determine whether D1 and D2 genotypes were associated with ovarian cancer risk, and whether the associations were modified by lactose and dairy food consumption.

\section{Materials and Methods}

\section{Study populations}

Data and specimens from the NECC were from two enrollment phases (1992-1997, 19982002). Details regarding case and control enrollment were described previously (16). The NECC study includes 1,231 epithelial ovarian cancer cases and 1,243 population-based controls residing in Massachusetts and New Hampshire. At study enrollment, participants were asked to recall known and putative ovarian cancer risk factors that occurred at least one year before diagnosis (for cases) or enrollment (controls) and $>95 \%$ of the participants provided a blood specimen. Institutional review boards at Brigham and Women's Hospital and Dartmouth Medical School approved the study and all participants provided written informed consent. 
The Nurses' Health Study (NHS) cohort was formed in 1976 when 121,700 female registered nurses, 30-55 years old and residing in 11 U.S. states, completed an initial questionnaire. The NHSII began in 1989 when 116,430 female registered nurses, aged 2542 , from 14 U.S. states completed a similar questionnaire. Both cohorts have been followed using biennially mailed questionnaires to update exposure information, including data on known and putative ovarian cancer risk factors and to ascertain non-fatal incident diseases. Follow-up rates at each questionnaire cycle were $~ 90 \%$ and $85 \%$ for the NHS and NHSII, respectively. In 1989-1990, 32,826 NHS participants submitted a blood sample (17) and follow-up of the NHS blood cohort was 98\% in 2006. Between 2001-2004, 33,040 NHS women without a blood sample provided a buccal cell specimen using a mouthwash protocol. Between 1996-1999, 29,611 NHSII participants provided blood samples (18) and follow-up of the NHSII blood cohort was $98 \%$ in 2003. The NHS studies were approved by the Committee on the Use of Human Subjects in Research at the Brigham and Women's Hospital.

The characteristics of the NECC and NHS/NHSII study populations were previously reported (19). Briefly, these studies included 992 cases and 1,050 frequency-matched controls from the NECC and 240 cases and 900 matched controls (matched on month/year of birth, DNA source and menopausal status at diagnosis) from the NHS/NHSII. For the cohorts, cases were diagnosed before June 1, 2006 (NHS) and June 1, 2003 (NHSII) and we included all cases with a DNA specimen collected prior to diagnosis as well as cases who provided a DNA specimen within four years after diagnosis (19). Cases and controls were matched on postmenopausal hormone use, the month/year, time of day and fasting status at blood draw (20). Distributions for most ovarian cancer risk factors and the mean reported intakes of lactose and dairy foods were similar across studies; however, the NHS participants were older and more likely to be parous while the NECC participants reported a higher proportion and longer duration of oral contraceptive (OC) use (data not shown).

Diet was assessed every four years through a validated self-administered, semi-quantitative FFQ starting in 1980 (NHS), 1991 (NHSII) or at enrollment (NECC). Respondents were asked about their frequency of intake of individual dairy products and these were converted to a continuous measure of servings/day using the median value within each frequency category (1-3 per month, 1, 2-4 or 5-6 per week, 1, 2-3, 4-5, 6 or more per day) which were converted to servings/day $(0.07,0.14,0.43,0.79,1,2.5,4.5$ and 6$)$, respectively. Lactose consumption was calculated by multiplying the frequency of intake by the nutrient content of specified portions of dairy products. For example, in the NHS cohort in 2002, $63 \%$ of total dietary lactose came from skim/low fat milk, $15 \%$ from yogurt, $3 \%$ from whole milk, $2 \%$ from cottage cheese and $0.9 \%$ from hard cheeses. Energy-adjusted lactose intake was calculated using the nutrient residual method. To maintain comparability with the NECC on the time period of exposure, we analyzed the cumulative average dietary intake up to two years prior to the diagnosis date for each case and their matched controls in the NHS/ NHSII. Study specific tertiles for lactose and dairy food intake were calculated based on the distribution in control subjects, and tertile cutpoints were chosen to maximize power.

\section{Genotyping}

DNA was extracted from the buffy coat or cheek cells using a Qiagen DNA extraction kit (Valencia, CA) and genotyping for the N314D variant and the 4-bp deletion (-119delGTCA) was performed on whole genome amplified DNA using the $5^{\prime}$ nuclease assay (Taqman) on the ABI PRISM 7900HT Sequence Detection System (Applied Biosystems, Foster City, $\mathrm{CA})$ at the Dana Farber/Harvard Cancer Center High Throughput Genotyping Core. Individuals with at least one copy of N314D and at least one copy of the 4-bp deletion were classified as the D2 genotype; those with at least once copy of N314D (but no 4-bp deletion) were D1. Laboratory personnel were blinded to case-control status and each plate included 
replicate samples for quality control, which had $100 \%$ concordance. Over $92 \%$ of the samples were successfully genotyped.

\section{Statistical analysis}

A chi-square test was used to evaluate Hardy-Weinberg equilibrium for N314D genotype frequencies. Chi-square tests were used to compare the distribution of each genotype by case-control status and by sample type (cheek vs. buffy coat). All analyses were conducted separately in the NHS/NHSII and the NECC populations using consistent exposure and covariate definitions and, after testing for heterogeneity in the results, the estimates were pooled using a random effects model (21). Unconditional (NECC) and conditional logistic regression (NHS/NHSII) was applied to estimate the odds ratio (an estimate of relative risk) and $95 \%$ confidence intervals for the main effect of the D1 or D2 genotype.

Analyses were restricted to white women due to ethnic variation in the allelic distribution of N314D (22). All multivariable analyses were adjusted for parity, OC use and family history of breast/ovarian cancer, and the NECC study was additionally adjusted for age, study center and body mass index. In the NHS, we used covariate data from two years prior to the diagnosis date for each case and their matched controls. Additional covariates were evaluated as potential confounders (smoking or menopausal status, postmenopausal hormone use, breastfeeding and tubal ligation) but were not included in the final model because they did not substantially alter the risk estimates.

To assess effect modification by dairy food and lactose consumption, we used unconditional logistic regression (additionally adjusting for age and DNA source in the NHS/NHSII) to model the association between D1 or D2 genotypes and ovarian cancer risk within each intake stratum, and calculated the $P$-value for interaction using the chi-square test for the difference between the log likelihoods for models with and without multiplicative interaction terms. Analyses were performed using SAS 9.2 (SAS Institute Inc., Cary, NC).

\section{Results}

No association was observed between the D1 or D2 genotypes and ovarian cancer risk (pooled RR $=1.1(95 \% \mathrm{CI}, 0.8-1.5)$ for D1 and 1.0 (95\% CI, 0.7-1.4) for D2) (Table 1). We observed similar associations in analyses by histologic subtype (serous invasive/borderline, endometrioid/clear cell) (data not shown). Among 23 NECC and 10 NHS/NHSII individuals with two copies of D2 and a presumed 50\% reduction in GALT activity, this genotype was not related to case-control status, although $42 \%$ of the 12 NECC cases had an endometrioid histology (Table 2).

We did not observe an association between ovarian cancer risk and consumption of lactose or individual dairy foods (skim/low fat milk, whole milk, yogurt, cottage/ricotta cheese, hard cheeses) (data not shown). When stratifying by lactose or skim/low fat milk intake, we observed no associations between the D1 or D2 genotype and ovarian cancer risk in any strata $\left(P_{\text {interaction }} \geq 0.3\right)$ (Table 3$)$. We also observed no associations between D1 or D2 genotypes and ovarian cancer risk when we stratified by reported intake of whole milk, yogurt, hard cheese or cottage/ricotta cheese (data not shown). We observed no association between the D1 or D2 genotypes and risk of serous invasive ovarian cancer in similar comparisons stratified by lactose and dairy food intake (data not shown).

\section{Discussion}

Our results do not support the hypothesis that the D1 or D2 genotypes alone or in conjunction with dairy or lactose consumption are associated with risk of ovarian cancer. 
This is consistent with previous reports of no association between GALT enzyme activity or N314D mutation and ovarian cancer risk (9-13). We confirmed our prior observation in an overlapping dataset (15) that endometrioid cases were more likely to have two copies of D2, although this was based on small numbers. To explain the increased risk of ovarian cancer associated with high levels of lactose intake, Cramer et al. (3) hypothesized that dietary galactose could increase risk by causing primary ovarian insufficiency and depletion of oocytes leading to subsequent gonadotropin stimulation of the ovaries (23). In the current study, D2 carriers with a presumed $25 \%$ reduction in GALT activity did not appear to have increased risk of ovarian cancer. In support of our findings, there have been no reports of ovarian dysfunction among women with Duarte galactosemia (24) (i.e., among patients with a G/D2 genotype who demonstrate $\sim 75 \%$ reduced GALT activity, the ' $G$ ' allele is a classic galactosemia allele).

Strengths of this study include our ability to evaluate the D1 and D2 genotypes separately for the first time in relation to ovarian cancer risk in two independent study populations, one with a large number of cases and the other with prospective data on diet and ovarian cancer incidence. Limitations include the retrospective assessment of dietary intake in the case control study, however the consistency in the NECC study and the NHS/NHSII results (collected prospectively) suggests that bias related to study design was not a major issue. Testing a large enough sample size was an issue; the minimum detectable Odds Ratio (OR) in our study at $80 \%$ power (type I error of $5 \%$ ) was 1.30 . Given that many genetic associations have smaller ORs, we cannot rule out a more modest association. To address the limitation of sample size, further studies that evaluate the D1/D2 genotypes in a largescale pooled analysis would be useful. The 4-bp deletion cannot be identified using data from GWAS and therefore genotyping or high-throughput assays such as the allele-specific PCR described by Carney et al. (8) would be needed to distinguish the D1 and D2 genotypes.

In summary, excess galactose has been hypothesized to lead to increased risk of ovarian cancer and has been linked to other reproductive outcomes such as infertility (25). In the current study, functional genetic variants in $G A L T$ did not appear to play an important role in this pathway nor in relation to ovarian cancer risk, even among the subgroup of individuals with the highest lactose intake. It would be of value to evaluate genetic variation in other genes that encode key enzymes that play a role in the metabolism of dietary galactose ( $G A L E, G A L K$ ) and to further interrogate other genetic variants in GALT in relation to risk of reproductive outcomes and/or ovarian cancer in studies that can integrate these findings with dietary galactose intake. These studies may provide important new insights into the potential associations between galactose intake, possible ovarian dysfunction, and the link with ovarian cancer.

\section{Acknowledgments}

Supported by the National Cancer Institute, NIH grants P50 CA105009, P01 CA87969, R01 CA49449, R01 CA50385, R01 CA67262, R01 CA054419 and the R25 CA098566 training grant.

We thank Hardeep Ranu, Pati Soule, Shireen Sarraf, and Jason Wong for laboratory and technical assistance and the participants of the NECC and the NHS for their dedication to these studies and contribution to this research. We thank the following state cancer registries for their help: AL, AZ, AR, CA, CO, CT, DE, FL, GA, ID, IL, IN, IA, KY, LA, ME, MD, MA, MI, NE, NH, NJ, NY, NC, ND, OH, OK, OR, PA, RI, SC, TN, TX, VA, WA, and WY.

\section{References}

1. Genkinger JM, Hunter DJ, Spiegelman D, Anderson KE, Arslan A, Beeson WL, et al. Dairy products and ovarian cancer: a pooled analysis of 12 cohort studies. Cancer Epidemiol Biomarkers Prev. 2006; 15:364-72. [PubMed: 16492930] 
2. Larsson SC, Orsini N, Wolk A. Milk, milk products and lactose intake and ovarian cancer risk: a meta-analysis of epidemiological studies. Int J Cancer. 2006; 118:431-41. [PubMed: 16052536]

3. Cramer DW, Harlow BL, Willett WC, Welch WR, Bell DA, Scully RE, et al. Galactose consumption and metabolism in relation to the risk of ovarian cancer. Lancet. $1989 ; 2: 66-71$. [PubMed: 2567871]

4. Elsas LJ, Dembure PP, Langley S, Paulk EM, Hjelm LN, Fridovich-Keil J. A common mutation associated with the Duarte galactosemia allele. Am J Hum Genet. 1994; 54:1030-6. [PubMed: 8198125]

5. Elsas LJ, Lai K, Saunders CJ, Langley SD. Functional analysis of the human galactose-1-phosphate uridyltransferase promoter in Duarte and LA variant galactosemia. Mol Genet Metab. 2001; 72:297-305. [PubMed: 11286503]

6. Trbusek M, Francova H, Kozak L. Galactosemia: deletion in the $5^{\prime}$ upstream region of the GALT gene reduces promoter efficiency. Hum Genet. 2001; 109:117-20. [PubMed: 11479743]

7. Kozak L, Francova H, Pijackova A, Macku J, Stastna S, Peskovova K, et al. Presence of a deletion in the $5^{\prime}$ upstream region of the GALT gene in Duarte (D2) alleles. J Med Genet. 1999; 36:576-8. [PubMed: 10424825]

8. Carney AE, Sanders RD, Garza KR, McGaha LA, Bean LJ, Coffee BW, et al. Origins, distribution and expression of the Duarte-2 (D2) allele of galactose-1-phosphate uridylyltransferase. Hum Mol Genet. 2009; 18:1624-32. [PubMed: 19224951]

9. Cozen W, Peters R, Reichardt JK, Ng W, Felix JC, Wan P, et al. Galactose-1-phosphate uridyl transferase (GALT) genotype and phenotype, galactose consumption, and the risk of borderline and invasive ovarian cancer (United States). Cancer Causes Control. 2002; 13:113-20. [PubMed: 11936817]

10. Fung WL, Risch H, McLaughlin J, Rosen B, Cole D, Vesprini D, et al. The N314D polymorphism of galactose-1-phosphate uridyl transferase does not modify the risk of ovarian cancer. Cancer Epidemiol Biomarkers Prev. 2003; 12:678-80. [PubMed: 12869412]

11. Goodman MT, Wu AH, Tung KH, McDuffie K, Cramer DW, Wilkens LR, et al. Association of galactose-1-phosphate uridyltransferase activity and N314D genotype with the risk of ovarian cancer. Am J Epidemiol. 2002; 156:693-701. [PubMed: 12370157]

12. Herrinton LJ, Weiss NS, Beresford SA, Stanford JL, Wolfla DM, Feng Z, et al. Lactose and galactose intake and metabolism in relation to the risk of epithelial ovarian cancer. Am J Epidemiol. 1995; 141:407-16. [PubMed: 7879785]

13. Webb PM, Bain CJ, Purdie DM, Harvey PW, Green A. Milk consumption, galactose metabolism and ovarian cancer (Australia). Cancer Causes Control. 1998; 9:637-44. [PubMed: 10189050]

14. Morland SJ, Jiang X, Hitchcock A, Thomas EJ, Campbell IG. Mutation of galactose-1-phosphate uridyl transferase and its association with ovarian cancer and endometriosis. Int J Cancer. 1998; 77:825-7. [PubMed: 9714048]

15. Cramer DW, Greenberg ER, Titus-Ernstoff L, Liberman RF, Welch WR, Li E, et al. A case-control study of galactose consumption and metabolism in relation to ovarian cancer. Cancer Epidemiol Biomarkers Prev. 2000; 9:95-101. [PubMed: 10667469]

16. Terry KL, De Vivo I, Titus-Ernstoff L, Sluss PM, Cramer DW. Genetic variation in the progesterone receptor gene and ovarian cancer risk. Am J Epidemiol. 2005; 161:442-51. [PubMed: 15718480]

17. Hankinson SE, Willett WC, Manson JE, Hunter DJ, Colditz GA, Stampfer MJ, et al. Alcohol, height, and adiposity in relation to estrogen and prolactin levels in postmenopausal women. J Natl Cancer Inst. 1995; 87:1297-302. [PubMed: 7658481]

18. Tworoger SS, Sluss P, Hankinson SE. Association between plasma prolactin concentrations and risk of breast cancer among predominately premenopausal women. Cancer Res. 2006; 66:247682. [PubMed: 16489055]

19. Gates MA, Tworoger SS, Terry KL, Titus-Ernstoff L, Rosner B, De Vivo I, et al. Talc use, variants of the GSTM1, GSTT1, and NAT2 genes, and risk of epithelial ovarian cancer. Cancer Epidemiol Biomarkers Prev. 2008; 17:2436-44. [PubMed: 18768514] 
20. Tworoger SS, Lee IM, Buring JE, Rosner B, Hollis BW, Hankinson SE. Plasma 25hydroxyvitamin D and 1,25-dihydroxyvitamin D and risk of incident ovarian cancer. Cancer Epidemiol Biomarkers Prev. 2007; 16:783-8. [PubMed: 17416771]

21. DerSimonian R, Laird N. Meta-analysis in clinical trials. Control Clin Trials. 1986; 7:177-88. [PubMed: 3802833]

22. Suzuki M, West C, Beutler E. Large-scale molecular screening for galactosemia alleles in a panethnic population. Hum Genet. 2001; 109:210-5. [PubMed: 11511927]

23. Cramer D, Welch WR. Determinants of ovarian cancer risk. II. Inferences regarding pathogenesis. J Natl Cancer Inst. 1983; 71:717-21. [PubMed: 6578367]

24. Fridovich-Keil JL, Gubbels CS, Spencer JB, Sanders RD, Land JA, Rubio-Gozalbo E. Ovarian function in girls and women with GALT-deficiency galactosemia. J Inherit Metab Dis. 2011; 34:357-66. [PubMed: 20978943]

25. Cramer DW, Harlow BL, Barbieri RL, Ng WG. Galactose-1-phosphate uridyl transferase activity associated with age at menopause and reproductive history. Fertil Steril. 1989; 51:609-15.

[PubMed: 2538369] 




Fertil Steril. Author manuscript; available in PMC 2013 September 01. 


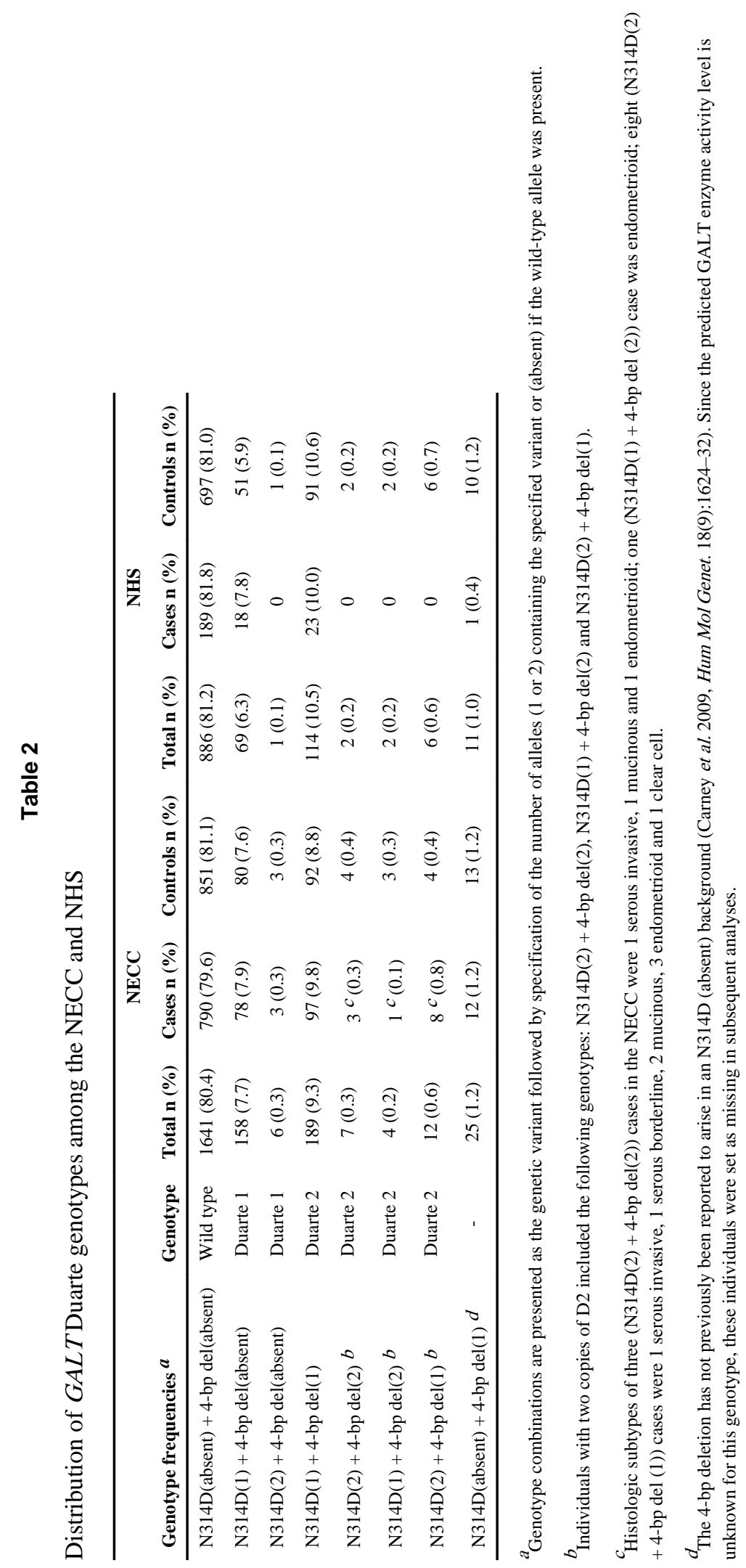

Fertil Steril. Author manuscript; available in PMC 2013 September 01. 
Table 3

Association between $G A L T$ Duarte genotypes and risk of ovarian cancer stratified by lactose or skim/low fat milk consumption in the NECC and the NHS

\begin{tabular}{|c|c|c|c|c|}
\hline & GALT genotype & $\begin{array}{c}\text { NECC } \\
\operatorname{RR}^{a}(95 \% \mathrm{CI})\end{array}$ & $\begin{array}{c}\text { NHS } \\
\operatorname{RR}^{b}{ }_{(95 \% ~ C I)}\end{array}$ & $\begin{array}{c}\text { Pooled }^{d} \\
\mathrm{RR}^{c}(95 \% \mathrm{CI})\end{array}$ \\
\hline \multicolumn{5}{|c|}{ Lactose (percentile) ${ }^{e}$} \\
\hline \multirow{3}{*}{$0 \leq 32$} & Wild type & $1.0(\mathrm{ref})$ & 1.0 (ref) & $1.0(\mathrm{ref})$ \\
\hline & Duarte 1 & $1.2(0.7-2.3)$ & $1.3(0.5-3.4)$ & $1.3(0.8-2.1)$ \\
\hline & Duarte 2 & $1.8(1.0-3.0)$ & $0.6(0.3-1.4)$ & $1.1(0.4-3.0)^{d}$ \\
\hline \multirow{3}{*}{$33 \leq 65$} & Wild type & $1.0(\mathrm{ref})$ & $1.0(\mathrm{ref})$ & $1.0(\mathrm{ref})$ \\
\hline & Duarte 1 & $1.1(0.6-1.9)$ & $1.3(0.5-3.2)$ & $1.1(0.7-1.8)$ \\
\hline & Duarte 2 & $0.9(0.5-1.6)$ & $0.7(0.3-1.7)$ & $0.9(0.6-1.4)$ \\
\hline \multirow{3}{*}{$\geq 66$} & Wild type & $1.0(\mathrm{ref})$ & $1.0(\mathrm{ref})$ & 1.0 (ref) \\
\hline & Duarte 1 & $0.8(0.4-1.6)$ & $1.5(0.5-4.7)$ & $1.0(0.6-1.7)$ \\
\hline & Duarte 2 & $0.8(0.5-1.4)$ & $1.2(0.5-3.0)$ & $0.9(0.6-1.5)$ \\
\hline$P$ interaction $f$ & & 0.3 & 0.9 & \\
\hline \multicolumn{5}{|c|}{ Skim/low fat milk (percentile) $g$} \\
\hline & Wild type & 1.0 (ref) & $1.0(\mathrm{ref})$ & $1.0(\mathrm{ref})$ \\
\hline \multirow[t]{3}{*}{$0 \leq 32$} & Duarte 1 & $1.6(0.8-3.2)$ & $1.8(0.7-4.7)$ & $1.7(1.0-2.9)$ \\
\hline & Duarte 2 & $1.5(0.8-2.8)$ & $0.7(0.3-1.6)$ & $1.1(0.5-2.3)$ \\
\hline & Wild type & $1.0(\mathrm{ref})$ & $1.0(\mathrm{ref})$ & $1.0(\mathrm{ref})$ \\
\hline \multirow[t]{3}{*}{$33 \leq 65$} & Duarte 1 & $0.8(0.5-1.5)$ & $0.8(0.3-2.2)$ & $0.8(0.5-1.4)$ \\
\hline & Duarte 2 & $1.0(0.6-1.6)$ & $1.1(0.5-2.3)$ & $1.0(0.7-1.5)$ \\
\hline & Wild type & $1.0(\mathrm{ref})$ & $1.0(\mathrm{ref})$ & 1.0 (ref) \\
\hline \multirow[t]{2}{*}{$\geq 66$} & Duarte 1 & $1.0(0.6-1.8)$ & $1.6(0.5-5.3)$ & $1.1(0.7-1.9)$ \\
\hline & Duarte 2 & $1.0(0.6-1.6)$ & $0.6(0.2-1.7)$ & $0.9(0.6-1.4)$ \\
\hline Pinteraction $f$ & & 0.5 & 0.6 & \\
\hline
\end{tabular}

${ }^{a}$ Unconditional logistic regression models adjusted for age (continuous), study center (MA or NH), parity (continuous: $0,1-2,3-4$ or $>5$ children), self-reported family history of breast or ovarian cancer, and (as categorical variables) duration of oral contraceptive use (never or $<3$ months, 3 months-<3 years, $3-5$ years, $>5$ years $)$ and body mass index $(<21,21-<23,23-<25,25-<30,>=30)$.

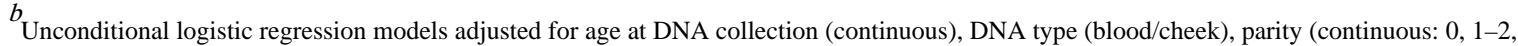
$3-4$ or $>5$ children), self-reported family history of breast or ovarian cancer, and duration of oral contraceptive use (categorical: never or <3 months, 3-<3 years, $3-5$ years, $>5$ years $)$.

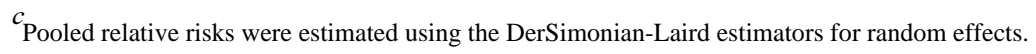


consumption $(P=0.04)$ and the remaining $P$ values for the lactose models were all $\geq 0.41$. For the skim/low fat milk models, all $P$ values for heterogeneity comparing the NECC and NHS/NHSII results were $\geq 0.14$.

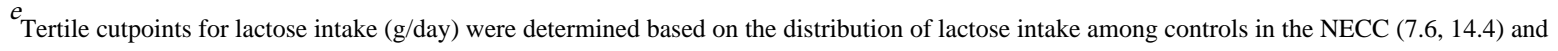
the NHS/NHSII (9.0, 16.1 and 10.0, 18.4 in the NHS and NHSII, respectively).

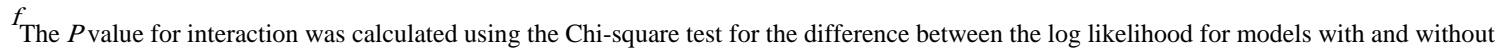
multiplicative interaction terms between diet stratum (lactose or skim/low fat milk) and Duarte genotypes. 


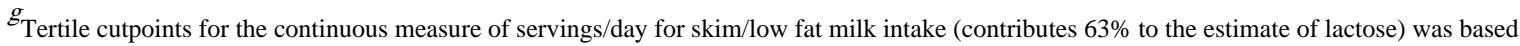
on the distribution of intake among controls in the NECC $(0.1,1.0)$ and the NHS/NHSII $(0.3,1.0$ and $0.2,1.0$ in the NHS and NHSII, respectively). 